\title{
Dynamics of end expiratory lung volume after changing positive end-expiratory pressure in acute respiratory distress syndrome patients
}

\author{
Aude Garnero ${ }^{1,2}$, David Tuxen³, Gaëlle Corno', Jacques Durand-Gasselin ${ }^{1}$, Carol Hodgson² \\ and Jean-Michel Arnal ${ }^{1,4^{*}}$
}

\begin{abstract}
Introduction: Lung recruitment maneuvers followed by an individually titrated positive end-expiratory pressure (PEEP) are the key components of the open lung ventilation strategy in acute respiratory distress syndrome (ARDS). The staircase recruitment maneuver is a step-by-step increase in PEEP followed by a decremental PEEP trial. The duration of each step is usually 2 minutes without physiologic rationale.
\end{abstract}

Methods: In this prospective study, we measured the dynamic end-expiratory lung volume changes ( $\Delta \mathrm{EELV})$ during an increase and decrease in PEEP to determine the optimal duration for each step. PEEP was progressively increased from 5 to $40 \mathrm{cmH}_{2} \mathrm{O}$ and then decreased from 40 to $5 \mathrm{cmH}_{2} \mathrm{O}$ in steps of $5 \mathrm{cmH}_{2} \mathrm{O}$ every 2.5 minutes. The dynamic of $\triangle \mathrm{EELV}$ was measured by direct spirometry as the difference between inspiratory and expiratory tidal volumes over 2.5 minutes following each increase and decrease in PEEP. $\Delta$ EELV was separated between the expected increased volume, calculated as the product of the respiratory system compliance by the change in PEEP, and the additional volume.

Results: Twenty-six early onset moderate or severe ARDS patients were included. Data are expressed as median [25th-75th quartiles]. During the increase in PEEP, the expected increased volume was achieved within 2[2-2] breaths. During the decrease in PEEP, the expected decreased volume was achieved within 1 [1-1] breath, and $95 \%$ of the additional decreased volume was achieved within 8 [2-15] breaths. Completion of volume changes in $99 \%$ of both increase and decrease in PEEP events required 29 breaths.

Conclusions: In early ARDS, most of the $\triangle E E L V$ occurs within the first minute, and change is completed within 2 minutes, following an increase or decrease in PEEP.

\section{Introduction}

Recruitment maneuvers and positive end-expiratory pressure (PEEP) are the key components of the open lung ventilation strategy in acute respiratory distress syndrome (ARDS) [1]. Lung recruitment maneuvers aim to reaerate collapsed or non-aerated distal airways and alveoli, and PEEP prevents derecruitment to improve oxygenation and decrease the risk of ventilator-induced lung injury [2]. Applied properly and early in selected

\footnotetext{
* Correspondence: jean-michel@arnal.org

'Service de réanimation polyvalente, Hôpital Sainte Musse, 54 Avenue Henri Sainte Claire Deville, 83056 Toulon, France

${ }^{4}$ Medical Research, Hamilton Medical, 8 Via Crusch, 7402 Bonaduz, Switzerland

Full list of author information is available at the end of the article
}

patients, lung recruitment may decrease ARDS mortality [3]. Several types of recruitment maneuvers have been described. Some use a rapid increase in pressure for a short period of time [4], whereas others use a more progressive increase in pressure. The staircase recruitment maneuver (SRM) is a step-by-step increase in PEEP with a constant driving pressure [5-8]. With each increase in PEEP, end-expiratory lung volume (EELV) increases as a result of distension of already aerated alveoli and recruitment of non-aerated lung units. However, at high levels of PEEP, there is a risk of hemodynamic compromise, especially if the step duration is prolonged. Each step length is usually 2 minutes without a strong physiologic rationale for such duration [5-8]. After the recruitment maneuver, an adequate level of PEEP is required to 
prevent derecruitment. The optimal PEEP setting can be determined by a decremental PEEP trial. PEEP is decreased step by step until part of the lung collapses again, which can be detected by a decrease in static compliance or transcutaneous oxygen saturation $\left(\mathrm{SpO}_{2}\right)$ [7-10]. During the decremental PEEP trial, each step length is usually maintained for $3-5$ minutes without a physiologic rationale for such duration [5-8].

The aim of the present study was to measure the dynamics of EELV changes ( $\triangle E E L V)$ after a step increase or decrease in PEEP ( $\triangle \mathrm{PEEP})$ to determine the optimal duration of steps during a SRM and a decremental PEEP trial.

\section{Material and methods}

This study was the second part of an analysis of a prospective interventional study (ClinicalTrials.gov identifier: NCT01899560) conducted between March and November 2013 in the 16-bed medical-surgical adult intensive care unit of Hôpital Sainte Musse, Toulon, France [11]. The study was approved by the local ethical review committee (Comité de Protection des Personnes Sud Méditérannée V), and informed consent was obtained from all patients or their next of kin before inclusion.

\section{Patients}

Eligible participants were all adults 18 years of age or older who had early-onset (less than $24 \mathrm{~h}$ ) moderate or severe ARDS according to the Berlin definition [12] and had been invasively ventilated for less than $72 \mathrm{~h}$ at the time of inclusion. Exclusion criteria were the following contraindications for a recruitment maneuver: bronchopleural fistula, emphysema, pneumothorax, antecedent of pneumothorax, increased intracranial pressure, pulmonary arterial hypertension with right heart failure as assessed by transthoracic echocardiography, hemodynamic instability with mean arterial pressure less than $65 \mathrm{mmHg}$, large pleural effusion as assessed by lung ultrasound, and pregnancy. Patients were mechanically ventilated using a Hamilton-S1 ventilator (Hamilton Medical, Bonaduz, Switzerland) in pressure control with $15 \mathrm{cmH}_{2} \mathrm{O}$ of driving pressure, 15 breaths per minute, inspiratory/expiratory ratio of 0.33 , and PEEP of 5 $\mathrm{cmH}_{2} \mathrm{O}$ [12]. The fraction of inspired oxygen $\left(\mathrm{FiO}_{2}\right)$ was adjusted to target a $\mathrm{SpO}_{2}$ between $90 \%$ and $94 \%$. A heated humidifier (MR850; Fisher \& Paykel Healthcare, Auckland, New Zealand) was used for inspiratory gas conditioning. The patients were in a semirecumbent position with the head of the bed at a 45-degree angle, and they were sedated with midazolam and sufentanil to target a Richmond Agitation Sedation Scale score of -5 . Cisatracurium was administered continuously [13] or in repeated injections during the procedure. The cuff of the endotracheal tube was transiently overinflated to 60 $\mathrm{cmH}_{2} \mathrm{O}$ before the start of the study protocol to prevent air leaks. Heart rate, invasive arterial pressure, and $\mathrm{SpO}_{2}$ were continuously monitored.

\section{Study protocol}

A SRM was performed as follows: PEEP was increased from $5 \mathrm{cmH}_{2} \mathrm{O}$ to $40 \mathrm{cmH}_{2} \mathrm{O}$ and then decreased from $40 \mathrm{cmH}_{2} \mathrm{O}$ to $5 \mathrm{cmH}_{2} \mathrm{O}$ in steps of $5 \mathrm{cmH}_{2} \mathrm{O}$ every 2.5 minutes. At the end of each step, airway pressure at end inspiration $\left(\mathrm{P}_{\mathrm{PLAT}}\right)$ and end expiration $\left(\mathrm{PEEP}_{\mathrm{TOT}}\right)$ was measured using a 5-second end-inspiratory and end-expiratory occlusion, respectively. Respiratory system compliance $\left(\mathrm{C}_{\mathrm{RS}}\right)$ was calculated as the ratio between tidal volume $\left(\mathrm{V}_{\mathrm{T}}\right)$ and the difference between $P_{\text {PLAT }}$ and PEEP ${ }_{\text {TOT }}: V_{\mathrm{T}} /\left(\mathrm{P}_{\text {PLAT }}-\right.$ PEEP $\left._{\text {TOT }}\right)$. The increase in PEEP was stopped, and the decrease was started at any level of PEEP if the patient developed bradycardia less than 60 beats per minute (bpm), tachycardia more than $140 \mathrm{bpm}$, arrhythmia, hypotension (systolic arterial pressure $<80 \mathrm{mmHg}$ or mean arterial pressure [MAP] $<55 \mathrm{mmHg}$ ), or hypoxemia $\left(\mathrm{SpO}_{2}<85 \%\right)$.

\section{Measurements and calculations}

Flow and airway pressure $\left(\mathrm{P}_{\mathrm{AW}}\right)$ were measured with a proximal pneumotachograph (linear between $-120 \mathrm{~L} / \mathrm{min}$ and $+120 \mathrm{~L} / \mathrm{min}$ with $\pm 5 \%$ [SD], PN279331; Hamilton Medical) positioned at the Y-piece. Volumes were integrated from flow measurements. Flow, volumes, and $\mathrm{P}_{\mathrm{AW}}$ were continuously recorded using Study Recorder software (Hamilton Medical) at $50 \mathrm{~Hz}$.

$\triangle$ EELV after a PEEP step was calculated by direct spirometry, which was shown to be a robust method compared with functional residual capacity measured by a washin/washout method with insoluble gases [14]. The difference between inspiratory and expiratory $V_{T}$ measured by direct spirometry was calculated for each breath following a PEEP step. This difference was corrected by the systematic difference, called $V_{T}$ offset, between inspired and expired $V_{\mathrm{T}}$, calculated from the last 30 seconds of the step, owing to humidity and temperature differences between inhaled and exhaled gas and oxygen consumption [15]. $\triangle E E L V$ was calculated as the cumulative difference between inspiratory and expiratory $V_{T}$, corrected by $\mathrm{V}_{\mathrm{T}}$ offset, measured over the 30 breaths following the PEEP step (Fig. 1). $\triangle E E L V$ was partitioned between the expected volume $\left(\mathrm{V}_{\mathrm{EXP}}\right)$ to distend already open alveoli (calculated as the product of $C_{R S}$ of the previous PEEP level by $\triangle$ PEEP) and the additional increased volume $\left(\mathrm{V}_{\mathrm{ADI}}\right)$ following the increase in PEEP. Thus, $\triangle E E L V=V_{E X P}+V_{A D I}$ for each level of PEEP. During the increase in PEEP, the number of breaths required to achieve $V_{\text {EXP }}$ to distend already open alveoli, as well as the number of breaths needed to achieve $95 \%$ of the $\mathrm{V}_{\mathrm{ADI}}$, 

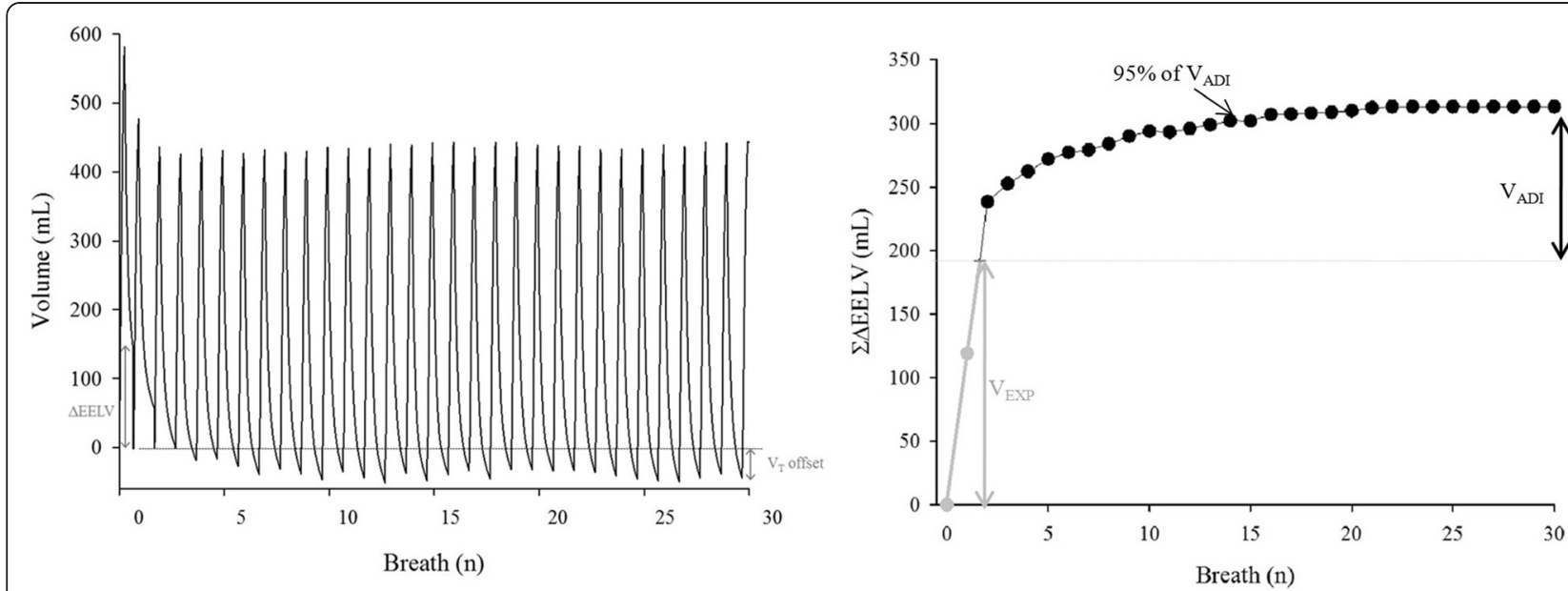

Fig. 1 Measurement of the dynamics of the end-expiratory lung volume change $(\Delta E E L V)$ after an increase in positive end-expiratory pressure (PEEP). Left panel displays the volume waveform for each breath following the increase in PEEP. The difference between inspired and expired tidal volumes $\left(V_{T}\right)$ was calculated and corrected by the volume offset. Right panel displays the dynamics of $\Delta$ EELV after the increase in PEEP. The difference between inspired and expired tidal volumes was reported breath by breath. The gray line is the expected increase in volume ( $V_{\text {EXP }}$ ) required to distend already open alveoli (calculated as the product of respiratory system compliance of the previous PEEP level by $\triangle P E E P$ ), and the black line is the additional volume $\left(\mathrm{V}_{\mathrm{ADI}}\right)$. The number of breaths needed to reach $95 \%$ of $\mathrm{V}_{\mathrm{ADI}}$ was measured

was calculated. The number of breaths required to ensure completion of the volume change in $99 \%$ of the increase in PEEP events was measured. During the decrease in PEEP, the number of breaths needed to achieve the expected decrease in volume $\left(\mathrm{V}_{\mathrm{EXP}}\right)$, as well as the number of breaths required to achieve $95 \%$ of the additional decreased volume $\left(\mathrm{V}_{\mathrm{ADD}}\right)$, was calculated. Thus, $\triangle \mathrm{EELV}=$ $\mathrm{V}_{\mathrm{EXP}}+\mathrm{V}_{\mathrm{ADD}}$ for each level of PEEP. The number of breaths required to ensure completion of volume change in $99 \%$ of the decrease in PEEP change events was measured.

\section{Statistical analysis}

The distribution of the data was assessed by KolmogorovSmirnov test. Data with normal distribution are presented as mean $\pm \mathrm{SD}$; others are expressed as median [25th-75th quartiles].

The numbers of breaths needed to achieve $95 \%$ of the volume change during increase and decrease in PEEP were compared using Student's $t$ test. The number of breaths required to achieve $95 \%$ of the additional volume according to each level of PEEP was tested using analysis of variance at both increase and decrease in PEEP. Statistic analyses were performed using SigmaStat version 3.5 and SigmaPlot version 11.0 software (Systat Software, San Jose, CA, USA).

\section{Results}

Twenty-six patients were analyzed. The characteristics of the population at inclusion and patient outcomes are presented in Table 1.
The increase in PEEP was stopped prematurely in eight patients because of hypotension with MAP less than $55 \mathrm{mmHg}$ (one patient at $25 \mathrm{cmH}_{2} \mathrm{O}$, two patients at 30 $\mathrm{cmH}_{2} \mathrm{O}$, and five patients at $35 \mathrm{cmH}_{2} \mathrm{O}$ ). Totals of 170 increases in PEEP and 170 decreases in PEEP were analyzed. Totals of 17 increases in PEEP and 11 decreases in PEEP

Table 1 Characteristics of the population at inclusion and patient outcomes

\begin{tabular}{|c|c|}
\hline Characteristics & Data \\
\hline Number of patients & 26 \\
\hline $\operatorname{Sex}(M / F)$ & $19 / 7$ \\
\hline Age $(y r)$ & $66 \pm 15$ \\
\hline SAPS $\|$ & $59 \pm 15$ \\
\hline Predicted body weight (kg) & $65 \pm 8$ \\
\hline Direct ARDS, n (\%) & $23(88 \%)$ \\
\hline Pneumonia, $\mathrm{n}$ & 8 \\
\hline Aspiration of gastric contents, $\mathrm{n}$ & 15 \\
\hline Indirect ARDS, n (\%) & $3(12 \%)$ \\
\hline Pancreatitis, $n$ & 1 \\
\hline Sepsis, $n$ & 2 \\
\hline $\mathrm{PaO}_{2} / \mathrm{FiO}_{2}(\mathrm{mmHg})$ & $116 \pm 37$ \\
\hline Static compliance $\left(\mathrm{ml} / \mathrm{cmH}_{2} \mathrm{O}\right)$ & $37 \pm 13$ \\
\hline Duration of invasive ventilation before inclusion (h) & $19 \pm 12$ \\
\hline Total duration of invasive ventilation (days) & $10 \pm 7$ \\
\hline Intensive care unit mortality, n (\%) & $8(30 \%)$ \\
\hline
\end{tabular}

Abbreviations: ARDS acute respiratory distress syndrome, $\mathrm{FiO}_{2}$ fraction of inspired oxygen, $\mathrm{PaO}_{2}$ partial pressure of oxygen, SAPS Simplified Acute Physiology Score

M/F: male/female, yr: years, kg: kilogram, $\mathrm{n}$ : number, \%: percentage, $\mathrm{mmHg}$ : millimeter of mercury, ml: milliliter, $\mathrm{cmH}_{2} \mathrm{O}$ : centimeter of water, $\mathrm{h}$ : hours 
were excluded owing to technical errors. Therefore, 153 increases in PEEP and 159 decreases in PEEP were reported.

During the increase in PEEP, $\mathrm{V}_{\text {EXP }}$ to distend already open alveoli was achieved within 2 [2] breaths. Ninetyfive percent of the $\mathrm{V}_{\mathrm{ADI}}$ was achieved within 13 [6-16] breaths (52 [24-64] s) (Fig. 2). Detailed results are presented in Tables 2 and 3. During the increase in PEEP, the dynamics of $\triangle E E L V$ were the same at all tested PEEP levels $(p=0.825)$ and were not correlated with $\mathrm{V}_{\mathrm{T}}\left(r^{2}=0.002\right)$ or $\mathrm{PaO}_{2} / \mathrm{FiO}_{2}$ ratio on admission $\left(r^{2}=0.170\right)$. Completion of volume change in $99 \%$ of the patients' PEEP increase events required 29 breaths (1 min, $56 \mathrm{~s}$ ) (Fig. 3).

During the decrease in PEEP, the expected decrease in volume was achieved within 1 [1] breath. Ninety-five percent of the $\mathrm{V}_{\mathrm{ADD}}$ was achieved within 8 [2-15] breaths (32 [8-60] s) (Fig. 2). Detailed results are presented in Tables 2 and 3. During the decrease in PEEP, the dynamic $\triangle E E L V$ remained the same at all tested PEEP levels $(p=0.114)$ and were not correlated with $\mathrm{V}_{\mathrm{T}}$ $\left(r^{2}=0.014\right)$ or $\mathrm{PaO}_{2} / \mathrm{FiO}_{2}$ ratio on admission $\left(r^{2}=0.002\right)$. Completion of volume change in $99 \%$ of the patient's PEEP decrease events required 29 breaths (1 min, $56 \mathrm{~s}$ ) (Fig. 3).

For completeness, the individual additional increased and decreased volumes are presented in Figs. 4 and 5, respectively. As shown, the single patient behavior is consistent with the median values in the majority of cases.

The number of breaths needed to reach $95 \%$ of the $\mathrm{V}_{\mathrm{ADI}}$ was higher than the number of breaths required to reach $95 \%$ of the $\mathrm{V}_{\mathrm{ADD}}(p=0.003)$.

\section{Discussion}

In the present study, most of the $\triangle E E L V$ during increase or decrease in PEEP occurred within the first minute and required 2 minutes to be completed. Change in
$95 \%$ of the additional volume during an increase in PEEP required more breaths than during the decrease in PEEP. If $\mathrm{V}_{\mathrm{ADI}}$ is assumed to be recruited volume following the increase in PEEP and $\mathrm{V}_{\mathrm{ADD}}$ is assumed to be derecruited volume following the decrease in PEEP, these results demonstrate a longer time course for $95 \%$ recruitment compared with $95 \%$ derecruitment but the same time course (1 min, $56 \mathrm{~s}$ ) for completion of volume change after a PEEP step. This supports the use of a 2minute step following both PEEP increases and decreases during a SRM if completion of volume change after each step is sought. A shorter time after PEEP changes ( $1 \mathrm{~min}$ ) could be used if $95 \%$ of volume change in $75 \%$ of PEEP change events is an acceptable endpoint.

In the present study, $95 \%$ of $\mathrm{V}_{\mathrm{ADI}}$ was achieved within 13 [6-16] breaths after an increase of PEEP. Katz et al. found that, in patients with mild ARDS, $90 \%$ of $\triangle E E L V$ was achieved after $4.6 \pm 1.4$ breaths [14]. Lung recruitment depends on applied pressure - namely, the transpulmonary pressure - and time [16]. To compare different studies and methods of recruitment, the time of exposure at high pressure needed to achieve $95 \%$ of recruitment was calculated as the product of the number of breaths by the inspiratory time $\left(\mathrm{T}_{\mathrm{I}}\right)$. In this study, $\mathrm{T}_{\mathrm{I}}$ was 1 second; therefore, 13 seconds of exposure at high pressure was required. In patients with severe ARDS, 14 seconds of exposure at high pressure was needed [17]. During a sustained inflation recruitment maneuver, the average time constant of the volume increase was $2.3 \pm 1.3$ seconds; thus, $95 \%$ of the recruitment occurred during the first 7 seconds [18]. The small difference between these results is due to the fact that this simple calculation considers not alveolar pressure but $\mathrm{P}_{\mathrm{AW}}$. In pressure-controlled mode, alveolar pressure is equal to $\mathrm{P}_{\mathrm{AW}}$ only at the end of $\mathrm{T}_{\mathrm{I}}$. However, the main finding is consistent among these studies: most of the recruitment (assessed by $\triangle E E L V$ ) occurs rapidly during a recruitment maneuver or after a PEEP
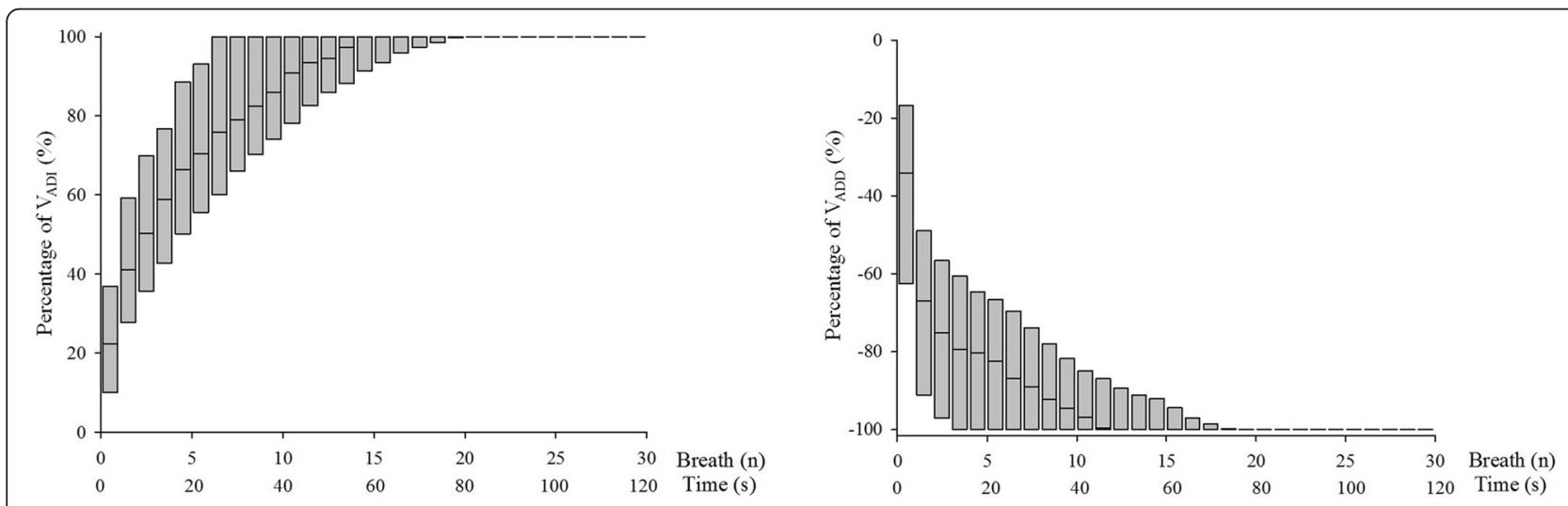

Fig. 2 Percentage of additional volume achieved according to the number of breaths. Box plot shows medians (25th-75th quartiles) for all patients at all positive end-expiratory (PEEP) levels. Left and right panels depict increases and decreases of PEEP, respectively. $V_{A D D}$ additional decreased volume, $V_{A D I}$ additional increased volume 
Table $2 \Delta E E L V, V_{E X P}, V_{A D}$, and $V_{A D} / \Delta E E L V$ ratios for each PEEP step when PEEP was increased and decreased

\begin{tabular}{lllll}
\hline PEEP steps $(\mathrm{s})$ & $\Delta$ EELV $(\mathrm{ml})$ & $V_{\text {EXP }}(\mathrm{ml})$ & $V_{\text {ADI }}(\mathrm{ml})$ & $\mathrm{V}_{\mathrm{AD}} / \Delta$ EELV $(\%)$ \\
\hline Increase in PEEP & & & & \\
$5-10$ & $309 \pm 124$ & $193 \pm 70$ & $116 \pm 81$ & $34 \pm 18$ \\
$10-15$ & $340 \pm 134$ & $196 \pm 63$ & $144 \pm 108$ & $37 \pm 20$ \\
$15-20$ & $328 \pm 178$ & $181 \pm 55$ & $147 \pm 140$ & $35 \pm 23$ \\
$20-25$ & $297 \pm 138$ & $174 \pm 44$ & $123 \pm 117$ & $36 \pm 17$ \\
$25-30$ & $290 \pm 148$ & $142 \pm 37$ & $154 \pm 140$ & $45 \pm 23$ \\
$30-35$ & $211 \pm 93$ & $129 \pm 34$ & $82 \pm 76$ & $33 \pm 19$ \\
$35-40$ & $203 \pm 102$ & $111 \pm 27$ & $89 \pm 98$ & $34 \pm 43$ \\
Mean \pm SD & $282 \pm 54$ & $161 \pm 33$ & $122 \pm 28$ & $36 \pm 4$ \\
Decrease in PEEP & & & & \\
$40-35$ & $182 \pm 133$ & $104 \pm 31$ & $78 \pm 114$ & $30 \pm 22$ \\
$35-30$ & $200 \pm 111$ & $120 \pm 31$ & $80 \pm 99$ & $33 \pm 18$ \\
$30-25$ & $218 \pm 72$ & $142 \pm 41$ & $76 \pm 45$ & $33 \pm 12$ \\
$25-20$ & $341 \pm 120$ & $169 \pm 55$ & $172 \pm 119$ & $46 \pm 18$ \\
$20-15$ & $384 \pm 174$ & $203 \pm 56$ & $181 \pm 140$ & $43 \pm 12$ \\
$15-10$ & $363 \pm 111$ & $232 \pm 61$ & $131 \pm 71$ & $35 \pm 12$ \\
$10-5$ & $384 \pm 177$ & $226 \pm 78$ & $158 \pm 122$ & $35 \pm 19$ \\
Mean \pm SD & $296 \pm 92$ & $171 \pm 51$ & $125 \pm 47$ & $36 \pm 6$
\end{tabular}

Abbreviations: EELV end-expiratory lung volume, PEEP positive end-expiratory pressure, $V_{A D I}$ additional increased volume, $V_{E X P}$ expected volume Numbers are the mean $\pm \mathrm{SD}$ of all patients increase. Small $\mathrm{V}_{\mathrm{ADI}}$ occurred beyond 1 minute up to 2 minutes after the PEEP step. Using electrical impedance tomography, it was possible to detect volume increases several minutes after the increase of PEEP $[19,20]$. These changes in volume are too small to be detected by direct spirometry. Interestingly, when PEEP is increased, most of the $\mathrm{PaO}_{2}$ change occurs within the first 5 minutes, but $\mathrm{PaO}_{2}$ still increases slowly so that the equilibrium is not achieved at $1 \mathrm{~h}$ after the PEEP change [10]. On one hand, a possible reason could be slow alveolar recruitment, a chest wall adaptation with a shift down of the diaphragm, an improvement in cardiac output, or a change in hypoxemic vascular constriction. On the other hand, static compliance change is achieved within 5 minutes. These results are in line with the mechanism of recruitment that is time-pressure dependent and thus a progressive phenomenon of a sequence of breaking liquid bridges [21].

After a decrease in PEEP, $95 \%$ of the $\mathrm{V}_{\mathrm{ADD}}$ was achieved within 8 [2-15] breaths. Katz et al. measured that $90 \%$ of $\triangle \mathrm{EELV}$ in patients with mild ARDS was achieved after $3.1 \pm 0.6$ breaths [14]. In the same way, the required time of exposure at PEEP needed to achieve $95 \%$ of derecruitment was calculated as the product of the number of breaths by the expiratory time $\left(T_{E}\right)$. In

Table $3 \Delta$ EELV and $V_{A D}$ at 1 and 2 minutes and ratio between 1 and 2 minutes during increase and decrease in PEEP

\begin{tabular}{|c|c|c|c|c|c|c|}
\hline PEEP step (s) & $\Delta \mathrm{EELV}$ at $1 \mathrm{~min}(\mathrm{ml})$ & $\Delta$ EELV total $(\mathrm{ml})$ & $\begin{array}{l}\Delta \mathrm{EELV} \text { at } 1 \mathrm{~min} / \Delta \mathrm{EELV} \\
\text { total }(\%)\end{array}$ & $\mathrm{V}_{\mathrm{ADI}}$ at $1 \mathrm{~min}(\mathrm{ml})$ & $\mathrm{V}_{\mathrm{ADI}}$ total $(\mathrm{ml})$ & $\begin{array}{l}\mathrm{V}_{\mathrm{ADI}} \text { at } 1 \mathrm{~min} / \mathrm{N}_{\mathrm{ADI}} \\
\text { total (\%) }\end{array}$ \\
\hline \multicolumn{7}{|c|}{ Increase in PEEP } \\
\hline $5-10$ & $299 \pm 118$ & $309 \pm 124$ & $97 \pm 4$ & $106 \pm 72$ & $116 \pm 81$ & $92 \pm 14$ \\
\hline $10-15$ & $326 \pm 127$ & $340 \pm 134$ & $96 \pm 4$ & $131 \pm 97$ & $144 \pm 108$ & $92 \pm 9$ \\
\hline $15-20$ & $319 \pm 166$ & $328 \pm 178$ & $98 \pm 3$ & $138 \pm 127$ & $147 \pm 140$ & $96 \pm 5$ \\
\hline $20-25$ & $284 \pm 124$ & $297 \pm 138$ & $97 \pm 5$ & $110 \pm 102$ & $123 \pm 117$ & $91 \pm 11$ \\
\hline $25-30$ & $275 \pm 130$ & $290 \pm 148$ & $96 \pm 5$ & $139 \pm 123$ & $154 \pm 1140$ & $92 \pm 11$ \\
\hline $30-35$ & $196 \pm 82$ & $211 \pm 93$ & $94 \pm 6$ & $68 \pm 68$ & $82 \pm 76$ & $81 \pm 25$ \\
\hline $35-40$ & $183 \pm 77$ & $203 \pm 102$ & $90 \pm 8$ & $72 \pm 71$ & $89 \pm 98$ & $50 \pm 35$ \\
\hline Mean \pm SD & $269 \pm 57$ & $282 \pm 54$ & $96 \pm 3$ & $109 \pm 30$ & $122 \pm 28$ & $85 \pm 16$ \\
\hline \multicolumn{7}{|c|}{ Decrease in PEEP } \\
\hline $40-35$ & $174 \pm 129$ & $182 \pm 133$ & $97 \pm 5$ & $70 \pm 111$ & $78 \pm 114$ & $92 \pm 14$ \\
\hline $35-30$ & $196 \pm 102$ & $200 \pm 111$ & $99 \pm 4$ & $75 \pm 90$ & $80 \pm 99$ & $100 \pm 13$ \\
\hline $30-25$ & $216 \pm 71$ & $218 \pm 72$ & $99 \pm 6$ & $74 \pm 44$ & $76 \pm 45$ & $98 \pm 28$ \\
\hline $25-20$ & $329 \pm 111$ & $341 \pm 120$ & $97 \pm 4$ & $160 \pm 110$ & $172 \pm 119$ & $95 \pm 7$ \\
\hline $20-15$ & $363 \pm 152$ & $384 \pm 174$ & $96 \pm 6$ & $160 \pm 115$ & $181 \pm 140$ & $91 \pm 12$ \\
\hline $15-10$ & $358 \pm 108$ & $363 \pm 111$ & $99 \pm 3$ & $126 \pm 69$ & $131 \pm 71$ & $96 \pm 8$ \\
\hline $10-5$ & $373 \pm 175$ & $384 \pm 177$ & $97 \pm 6$ & $150 \pm 114$ & $158 \pm 122$ & $89 \pm 23$ \\
\hline Mean $\pm S D$ & $287 \pm 88$ & $296 \pm 92$ & $98 \pm 1$ & $117 \pm 42$ & $125 \pm 47$ & $94 \pm 4$ \\
\hline
\end{tabular}



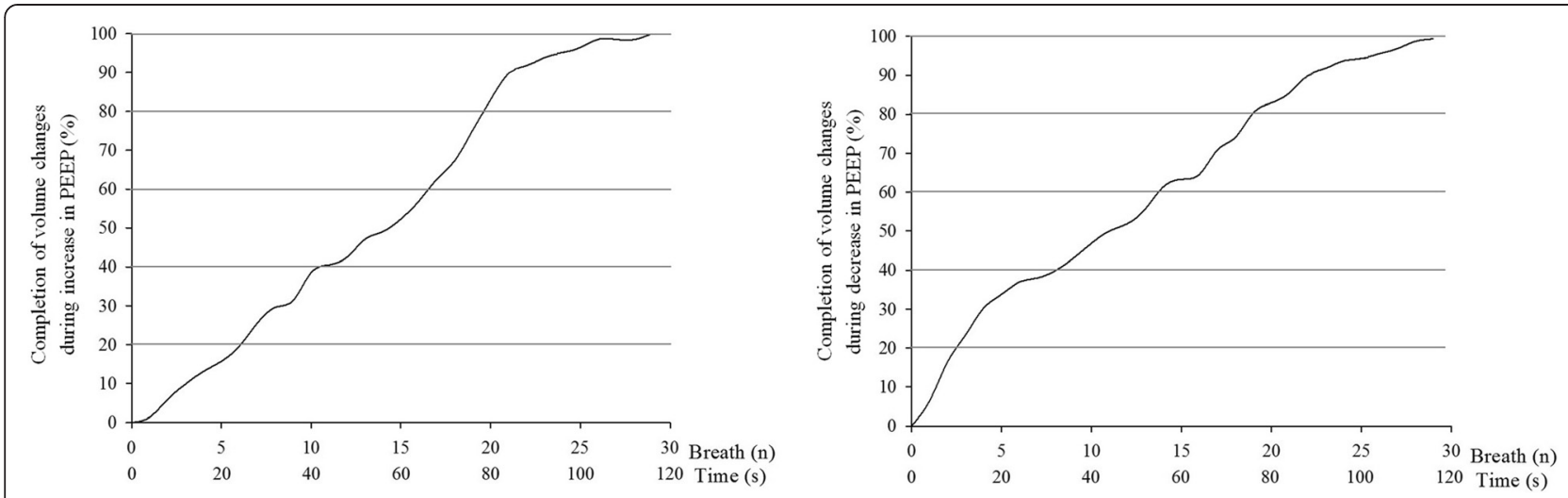

Fig. 3 Percentage of patients' positive end-expiratory pressure (PEEP) events that had completed volume change against the number of breaths needed to complete volume change. Left panel: Percentage of patients' PEEP increase events that had completed volume change plotted against the number of breaths required to complete volume change. Right panel: Percentage of patients' PEEP decrease events that had completed volume change plotted against the number of breaths needed to complete volume change

this study, $\mathrm{T}_{\mathrm{E}}$ was 3 seconds; therefore, 24 seconds was required. In patients with severe ARDS, $95 \%$ of the volume change was achieved within 17 seconds of exposure at PEEP [17]. This calculation is probably overestimated because alveoli pressure reaches PEEP only at the end of $\mathrm{T}_{\mathrm{E}}$. However, these results are consistent in that most of the mechanical derecruitment occurs rapidly after a decrease in PEEP. Interestingly, when PEEP is decreased, the equilibration time for arterial oxygenation is reached within 5 minutes [10]. These results support the mechanism of derecruitment as a passive phenomenon. The immediate collapse after decrease in PEEP is probably due to the gravity-dependent closure of small airways in the dependent part of the lung. Oxygenation-related variables could guide the decremental PEEP trial, but further investigations are necessary to determine the evolution of these variables during the five 5 minutes. If we consider that derecruitment increases the shunt fraction, decreases in $\mathrm{PaO}_{2}$ or $\mathrm{SaO}_{2}$ should occur rapidly after lung collapse. Conversely, static $\mathrm{C}_{\mathrm{RS}}$ takes longer to decrease and should not be very informative in tracking within the minutes following the PEEP step.

The number of breaths required to recruit seems to be more than the number of breaths needed to derecruit. Recruitment is an active, progressive phenomenon of a sequence of breaking liquid bridges whereas derecruitment is a passive phenomenon due to gravity.

This study has a number of important implications. Most patients have significant recruitment after most PEEP increases, from the lowest to the highest, with no clear critical recruitment level, suggesting that all patients should be taken to the highest PEEP level (40 $\mathrm{cmH}_{2} \mathrm{O}$ ) to maximize their recruitment. Furthermore, there was a concept that decremental PEEP was needed to find the critical PEEP level where derecruitment started to select a PEEP level at or above that level for clinical use. But again, although equivalent derecruitment did occur at lower PEEP levels, this study shows that most patients have significant derecruitment after most PEEP reductions, with no clear critical derecruitment level. This implies that the derecruitmentdetermined PEEP level would have to be based on a specified percentage (e.g., $10 \%$ or $20 \%$ ) of derecruitment, possibly depending on the hemodynamic and gas exchange consequences.

The main limitation of this study is that we do not know if the additional $\triangle E E L V$ is recruited volume, volume that overdistends already aerated units with a long time constant, or viscoelastance and chest wall adaptation, as we did not use any imaging of the thorax. Second, the direct spirometry method is not accurate enough to detect a $\triangle E E L V$ below $10 \mathrm{ml}$. Therefore, these results may represent most but not all of the $\triangle E E L V$. Third, in an animal study, the restitution of lung volume after suctioning was significantly slower during pressurecontrolled ventilation than during volume-controlled ventilation [22]. As our patients were ventilated in pressure-controlled mode, our results might have been different in volume-controlled mode. However, the breathing patterns are probably more important to explaining such differences than the mode itself. Fourth, these results concern sedated and paralyzed patients with ARDS, the population of interest in performing a SRM and decremental PEEP trial. In a spontaneously breathing patient, the time course of recruitment and derecruitment may be very different, as the inspiratory effort has a strong recruitment effect. Finally, this study included mainly ARDS caused by direct lung injury ( $88 \%$ ), in particular gastric aspiration. This is due to the case mix of our intensive care unit, which receives a lot of patients with coma or drug overdose complicated by gastric aspiration. Application of the results should be limited to this subgroup of 

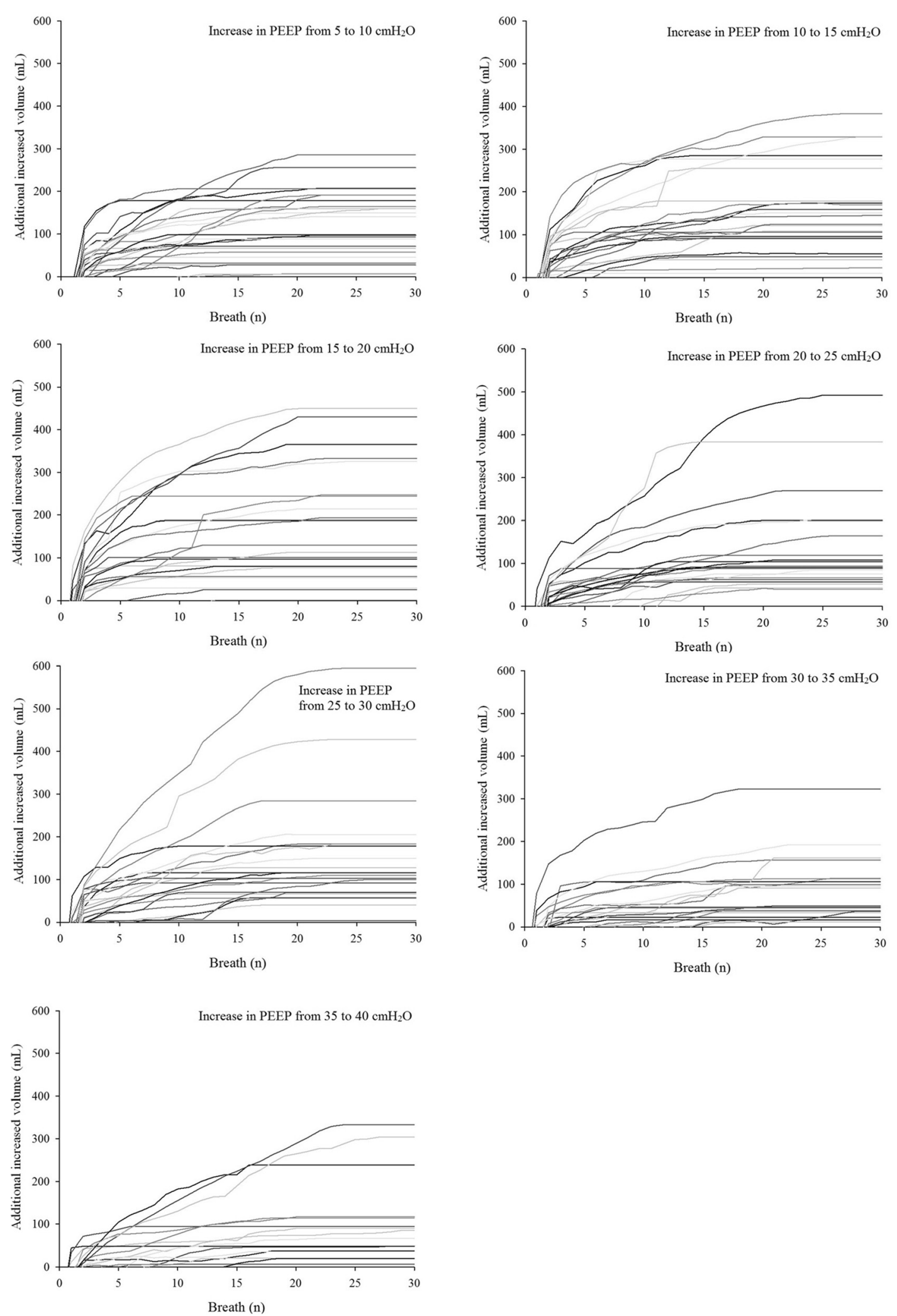

Fig. 4 Individual additional increased volume after increase in positive end-expiratory pressure (PEEP). The expected increase in volume was subtracted 

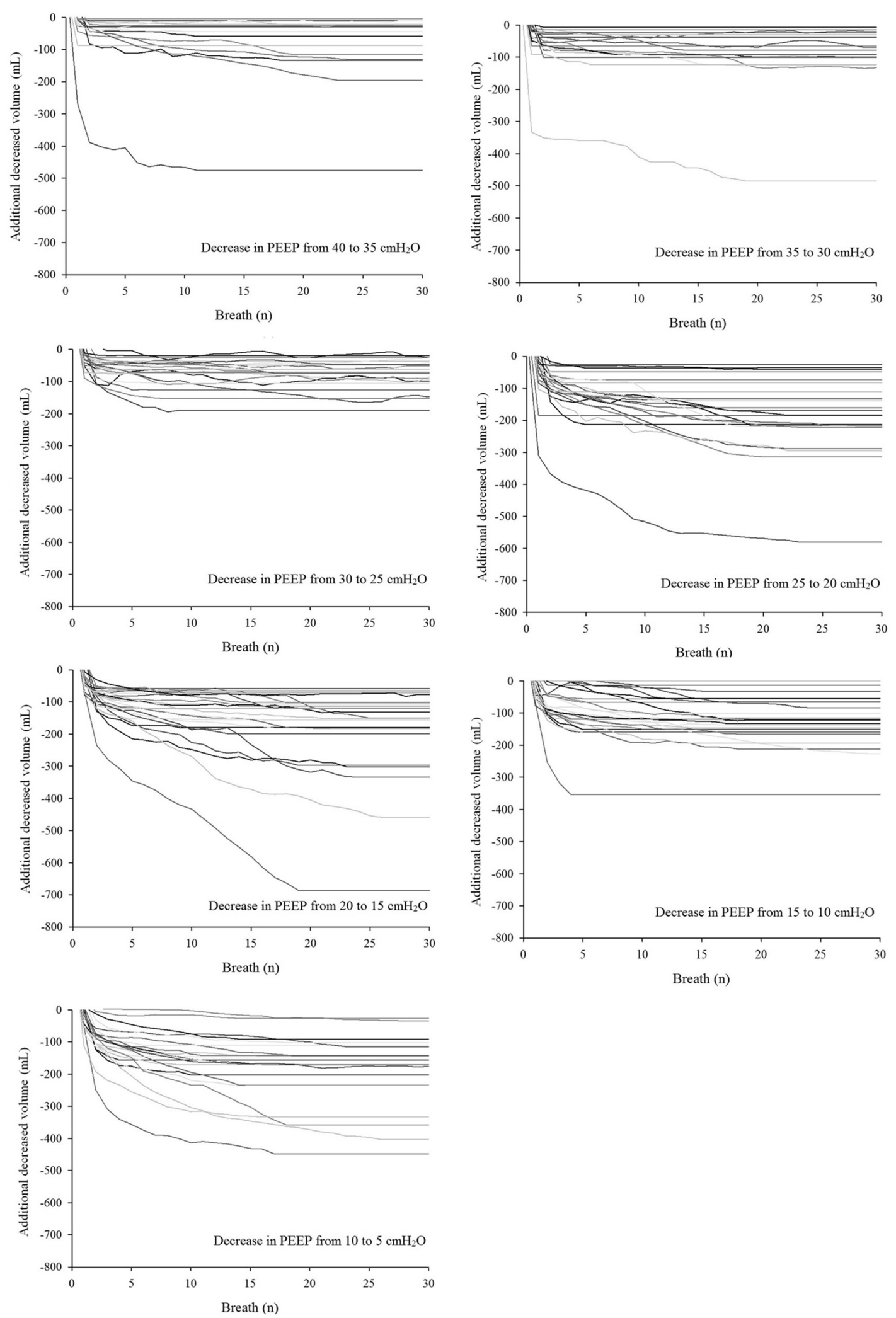

Fig. 5 Individual additional decreased volume after decrease in positive end-expiratory pressure (PEEP). The expected decrease in volume was subtracted 
the population, as the potentially recruitable lung in ARDS caused by indirect lung injury may be different [23].

In practice, these results support the use of a short duration for the PEEP step during a SRM: 1 minute to achieve most of the $\triangle E E L V$ and 2 minutes to achieve complete $\triangle E E L V$. For the decreasing PEEP trial, changes in $\triangle E E L V$ were even faster but difficult to assess at the bedside, so clinicians had to track oxygenation changes. For the moment, 5 minutes may be appropriate until we have data concerning the $\mathrm{SaO}_{2}$ changes during the first 5 minutes.

\section{Conclusions}

In patients with early-onset moderate to severe ARDS, most of the $\triangle E E L V$ occurs within the first minute and was completed within 2 minutes following an increase or decrease in PEEP. Dynamic EELV is faster after a decrease in PEEP than after an increase in PEEP. These results demonstrate that recruitment and derecruitment have different time courses and support the use of short duration (1-2 min) for the PEEP step during SRM and decremental PEEP trial.

\section{Key messages}

- What is the key question? How long does it take to reach a new steady state in end-expiratory lung volume after an increase and a decrease in PEEP?

- What is the bottom line? Most of the change in end-expiratory lung volume occurs within the first minute, and change is completed within 2 minutes following a PEEP increase or decrease.

- Why read on? To determine the optimal duration of the PEEP step during a recruitment maneuver and decremental PEEP trial.

\footnotetext{
Abbreviations

ARDS: acute respiratory distress syndrome; bpm: beats per minute; $C_{R S}$ : respiratory system compliance; EELV: end-expiratory lung volume; $\mathrm{FiO}_{2}$ : fraction of inspired oxygen; MAP: mean arterial pressure; $\mathrm{PaO}_{2}$ : partial pressure of oxygen; $P_{\text {AW: }}$ airway pressure; PEEP: positive end-expiratory pressure; PEEP TOT: airway pressure at end expiration; PPLAT: airway pressure at end inspiration; SAPS: Simplified Acute Physiology Score; $\mathrm{SpO}_{2}$ : oxygen saturation; SRM: staircase recruitment maneuver; $T_{\mathrm{E}}$ : expiratory time: $\mathrm{T}_{\mathrm{I}}$ : inspiratory time; $\mathrm{V}_{\mathrm{ADD}}$ : additional decreased volume; $\mathrm{V}_{\mathrm{ADI}}$ : additional increased volume; $V_{\text {EXP: }}$ : expected volume; $V_{T}$ : tidal volume.
}

\section{Competing interests}

JMA is working part-time as a medical research manager for Hamilton Medical. The other authors declare that they have no competing interests.

\section{Authors' contributions}

AG designed the study, wrote the protocol, collected data, analyzed the results and drafted the manuscript. CG and JDG made substantial contributions to collecting the data and revising the manuscript. DT and $\mathrm{CH}$ made substantial contributions to interpreting the results and revising the manuscript. JMA made a substantial contribution to writing the protocol, collecting data, analyzing the results and drafting the manuscript. All authors read and approved the final manuscript.

\section{Acknowledgements}

This study was promoted by the Centre Hospitalier Intercommunal de Toulon La Seyne sur Mer. The work was supported by the Association pour I'Assistance Respiratoire à Domicile (APARD). It was performed at the Service de réanimation polyvalente, Hôpital Sainte Musse, Toulon, France. The results reported here were previously presented in abstract form at the 2014 European Society of Intensive Care Medicine annual meeting in Barcelona [24].

\section{Author details}

${ }^{1}$ Service de réanimation polyvalente, Hôpital Sainte Musse, 54 Avenue Henri Sainte Claire Deville, 83056 Toulon, France. ${ }^{2}$ Australian and New Zealand Intensive Care Research Centre, Department of Epidemiology and Preventive Medicine, Monash University, The Alfred Centre, 99 Commercial Road, Melbourne, VIC 3004, Australia. ${ }^{3}$ Department of Intensive Care and Hyperbaric Medicine, Alfred Hospital, 55 Commercial Road, PO Box 315, Prahan, VIC 3181, Australia. ${ }^{4}$ Medical Research, Hamilton Medical, 8 Via Crusch, 7402 Bonaduz, Switzerland.

Received: 2 July 2015 Accepted: 21 August 2015

Published online: 18 September 2015

\section{References}

1. Caironi P, Cressoni M, Chiumello D, Ranieri M, Quintel M, Russo SG, et al. Lung opening and closing during ventilation of acute respiratory distress syndrome. Am J Respir Crit Care Med. 2010;181:578-86.

2. Crotti S, Mascheroni D, Caironi P, Pelosi P, Ronzoni G, Mondino M, et al. Recruitment and derecruitment during acute respiratory failure: a clinical study. Am J Respir Crit Care Med. 2001;164:131-40.

3. Suzumura EA, Figueiró M, Normilio-Silva K, Laranjeira L, Oliveira C, Buehler AM, et al. Effects of alveolar recruitment maneuvers on clinical outcomes in patients with acute respiratory distress syndrome: a systematic review and meta-analysis. Intensive Care Med. 2014;40:1227-40.

4. Lapinsky SE, Aubin M, Mehta S, Boiteau P, Slutsky AS. Safety and efficacy of a sustained inflation for alveolar recruitment in adults with respiratory failure. Intensive Care Med. 1999;25:1297-301.

5. de Matos GFJ, Stanzani F, Passos RH, Fontana MF, Albaladejo R, Caserta RE, et al. How large is the lung recruitability in early acute respiratory distress syndrome: a prospective case series of patients monitored by computed tomography. Crit Care. 2012;16:R4.

6. Borges JB, Okamoto VN, Matos GFJ, Caramez MP, Arantes PR, Barros F, et al. Reversibility of lung collapse and hypoxemia in early acute respiratory distress syndrome. Am J Respir Crit Care Med. 2006;174:268-78.

7. Hodgson CL, Tuxen DV, Davies AR, Bailey MJ, Higgins AM, Holland AE, et al. A randomised controlled trial of an open lung strategy with staircase recruitment, titrated PEEP and targeted low airway pressures in patients with acute respiratory distress syndrome. Crit Care. 2011;15:R133.

8. Hodgson CL, Tuxen DV, Bailey MJ, Holland AE, Keating JL, Pilcher D, et al. A positive response to a recruitment maneuver with PEEP titration in patients with ARDS, regardless of transient oxygen desaturation during the maneuver. J Intensive Care Med. 2011;26:41-9.

9. Maggiore SM, Jonson B, Richard JC, Jaber S, Lemaire F, Brochard L. Alveolar derecruitment at decremental positive end-expiratory pressure levels in acute lung injury: comparison with the lower inflection point, oxygenation, and compliance. Am J Respir Crit Care Med. 2001;164:795-801.

10. Chiumello D, Coppola S, Froio S, Mietto C, Brazzi L, Carlesso E, et al. Time to reach a new steady state after changes of positive end expiratory pressure. Intensive Care Med. 2013:39:1377-85.

11. Garnero A, Tuxen D, Ducros L, Demory D, Donati SY, Durand-Gasselin J, et al. Non-invasive assessment of lung elastance in patients with acute respiratory distress syndrome. Minerva Anestesiol. In press.

12. The ARDS Definition Task Force. Acute respiratory distress syndrome: the Berlin Definition. JAMA. 2012;307:2526-33.

13. Papazian L, Forel JM, Gacouin A, Penot-Ragon C, Perrin G, Loundou A, et al. Neuromuscular blockers in early acute respiratory distress syndrome. N Engl J Med. 2010;363:1107-16.

14. Katz JA, Ozanne GM, Zinn SE, Fairley HB. Time course and mechanisms of lung-volume increase with PEEP in acute pulmonary failure. Anesthesiology. 1981;54:9-16.

15. Stahl CA, Möller K, Schumann S, Kuhlen R, Sydow M, Putensen C, et al. Dynamic versus static respiratory mechanics in acute lung injury and acute respiratory distress syndrome. Crit Care Med. 2006;34:2090-8. 
16. Bates $\mathrm{JH}$, Irvin $\mathrm{CG}$. Time dependence of recruitment and derecruitment in the lung: a theoretical model. J Appl Physiol. 2002;93:705-13.

17. Fretschner R, Laubscher TP, Brunner JX. New aspects of pulmonary mechanics: "slowly" distensible compartments of the respiratory system, identified by a PEEP step maneuver. Intensive Care Med. 1996;22:1328-34.

18. Arnal JM, Paquet J, Wysocki M, Demory D, Donati S, Granier I, et al. Optimal duration of a sustained inflation recruitment maneuver in ARDS patients. Intensive Care Med. 2011;37:1588-94.

19. Wrigge H, Zinserling J, Muders T, Varelmann D, Günther U, von der Groeben C, et al. Electrical impedance tomography compared with thoracic computed tomography during a slow inflation maneuver in experimental models of lung injury. Crit Care Med. 2008;36:903-9.

20. Grivans C, Lundin S, Stenqvist O, Lindgren S. Positive end-expiratory pressure-induced changes in end-expiratory lung volume measured by spirometry and electric impedance tomography. Acta Anaesthesiol Scand. 2011;55:1068-77.

21. Brower RG. Editorial: Time to reach a new equilibrium after changes in PEEP in acute respiratory distress syndrome patients. Intensive Care Med. 2013;39:2053-5.

22. Lindgren S, Odenstedt H, Olegård C, Söndergaard S, Lundin S, Stenqvist O. Regional lung derecruitment after endotracheal suction during volume- or pressure-controlled ventilation: a study using electric impedance tomography. Intensive Care Med. 2007;33:172-80.

23. Gattinoni L, Pelosi P, Suter PM, Pedoto A, Vercesi P, Lissoni A. Acute respiratory distress syndrome caused by pulmonary and extrapulmonary disease: different syndromes? Am J Respir Crit Care Med. 1998;158:3-11.

24. Garnero A, Tuxen D, Embriaco N, Demory D, Donati SY, Durand-Gasselin J, et al. Dynamics of end expiratory lung volume after changing PEEP in ARDS patients [abstract 004]. Intensive Care Med. 2014;40:1-2. http://react-profile.org/Download/ESICM2014_Abstract_Book_final_ version.pdf. Accessed 2 September 2015.

\section{Submit your next manuscript to BioMed Central and take full advantage of:}

- Convenient online submission

- Thorough peer review

- No space constraints or color figure charges

- Immediate publication on acceptance

- Inclusion in PubMed, CAS, Scopus and Google Scholar

- Research which is freely available for redistribution 